\title{
ERRATUM
}

\section{Erratum to: Routine Rapid HIV Screening in Six Community Health Centers Serving Populations at Risk}

\author{
Janet J. Myers, PhD, MPH', Cheryl Modica, $P h D, M P H, B S N^{2}$, \\ Mi-Suk Kang Dufour, PhD(cand), $M P H^{7}$, Caryn Bernstein, $B S^{2}$, and Kathleen McNamara, $R N^{2}$ \\ ${ }^{1}$ Center for AIDS Prevention Studies, University of California, San Francisco, CA, USA; ${ }^{2}$ National Association of Community Health Centers, \\ Bethesda, MD, USA.
}

J Gen Intern Med 25(3):277

DOI: $10.1007 / \mathrm{s} 11606-009-1138-y$

(c) Society of General Internal Medicine 2009

$\mathrm{T}$ he original article contained inaccuracies regarding the outcomes of the 39 rapid tests resulting in preliminarily positive results. The true breakdown is as follows: As reported, 17 of the 39 tests were confirmed HIV infections. Nine of the 39 were determined to be false positives with either two western blot tests or RNA testing. Ten additional patients received only one confirmatory western blot test, all of which were negative. Three individuals did not receive confirmatory testing after the initial positive rapid test result. The authors regret this error.

Corresponding Author: Janet J. Meyers, PhD, MPH; Center for AIDS Prevention Studies, University of California, 50 Beale Street, Suite 1300, San Francisco, CA 94105, USA (e-mail: janet.myers@ ucsf.edu).

The online version of the original article can be found at http://dx.doi. org/10.1007/s11606-009-1070-1.

Published online November 24, 2009 